\title{
Modeling and forecasting the Algiers Stock Exchange returns using the Box-Jenkins methodology
}

\author{
Mohamed Samir Boudrioua \\ mohamedsamirboudrioua@gmail.com \\ R\&D Department \\ ORSI Company, Monastir, Tunisia.
}

\begin{abstract}
:
The Algiers Stock Exchange (ASE) is the only stock exchange in Algeria. It's one of the newest and smallest emerging stock exchanges in the world. The focus of this paper is to model and forecast monthly returns of the ASE index (DZAIRINDEX) using The Box- Jenkins methodology. The period of this study is from Jun 2010 to July 2019. According to Akaike's Information Criterion (AIC) estimator, the Seasonal Autoregressive Integrated Moving Average SARIMA $(2,0,0)(0,0,1)_{12}$ is chosen as the best model for forecasting the monthly DZAIRINDEX returns. Diagnostic tests confirm that the fitted model is adequate, where the residuals of this model are normally distributed with no autocorrelation and no heteroskedasticity.

The forecast of the monthly DZAIRINDEX returns for one year ahead using this model shows a decreasing fluctuations trend. Based on different measures of forecast accuracy such as ME, MAE, RMSE, MASE, we show that the forecast accuracy of $\operatorname{SARIMA}(2,0,0)(0,0,1)_{12}$ is acceptable and this model performs much better than a naïve model.

These results could be used by the financial communities in Algeria to deal with stock exchange risks and to improve their decisions.
\end{abstract}

Key Words: Algiers Stock Exchange, Box-Jenkins methodology, SARIMA model. 


\section{INTRODUCTION}

The Algiers Stock Exchange (ASE) is one of the newest and smallest stock exchanges in the world. Due to this fact, there aren't a lot of studies that focused on this emerging stock exchange. According to the ASE official website http://www.sgbv.dz, the official listing of Algiers Stock Exchange for transferable securities includes an equity securities market and a debt securities market. Where the market for equity securities comprises a Main market for large enterprises, and Small and mediumsized enterprises Market reserved for the Small and Medium Enterprises.

The main market includes five companies are SAIDAL Group activating in the pharmaceutical sector, EGH EL AURASSI activating in the tourism sector, ALLIANCE INSURANCE activating in the insurance sector, NCA-Rouiba activating in the agri-food sector and BIOPHARM activating in the pharmaceutical sector. The Algiers Stock Exchange uses a reference index called DZAIRINDEX includes the total listing companies in the main market.

The concept of forecasting stock market returns has become very important in finance, where it help investors to understand the stock market trend and make their decisions, minimize investment risks associated with the market and improve their returns (Lin and Yu, 2009). There are several methods of forecasting time series such as exponential smoothing methods, simultaneous-equation regression models and autoregressive integrated moving average models (ARIMA) models, Neural networks models and others (Gujarati, 2004). The most used and popular model in forecasting financial time series over Short time periods is the Box-Jenkins model or ARIMA model ( Box and Jenkins ,1970). The emphasis of these methods is on analyzing the stochastic properties of economic time series on their own (Gujarati, 2004). Box and Jenkins (1976) developed an extension of ARIMA model which is seasonal ARIMA (SARIMA) model to forecast seasonal time series. This model requires that the data be seasonally differenced to achieve stationarity condition.

Several studies have used the Box-Jenkins methodology for forecasting different stock markets in the world. Al-Shiab (2006) used the Box-Jenkins method to forecast the Amman stock exchange. Katircioglu1 and Al-khaza'leh (2016) applied the same method for forecasting services sector volatility in the Amman Stock Exchange. Wahyudi (2017) used also ARIMA model to forecast the Indonesia Stock Price. Ashik and Kannan (2017) forecasted National Stock Exchange in India using the same models. There are also many studies have applied this methodology in various fields of forecasting. For example, Wagner (2010) compared seasonal ARIMA model and vector time series model for forecasting daily demand in cash supply chains. Chang et al. (2012) forecasted monthly precipitation in Yantai, China with seasonal ARIMA model. The results of these studies show that this model performed well and gives less errors compared with other models over short time periods.

The objective of this study is to fit the best forecasting model for the Algiers Stock Exchange returns using the Box -Jenkins methodology. Monthly returns for the index DZAIRINDEX were used in this task over the period (Jun 2010-July 2019). A forecast for one year ahead was performed using 
the chosen model seasonal ARIMA $(2,0,0)(0,0,1)_{12}$. This forecast can help policymakers and investors in Algeria to make their decisions.

The rest of the paper is outlined as follows: Some literature review in section two. The third section describes the Box-Jenkins methodology. The fourth section presents the empirical findings with discussions. Finally we present the conclusion with some perspectives in the fifth section.

\section{LITERATURE REVIEW}

There is a large literature on forecasting stock exchanges using the Box-Jenkins methodology. AlShiab (2006) used a general daily index of the Amman Stock Exchange, over the period (4/1/2004 10/8/2004) to examine the univariate ARIMA forecasting model. He found that the forecast was not consistent with actual performance since the Amman Stock Exchange follow most closely the Efficient Market Hypothesis in its weak form, during the period of the prediction (11/8/2004-19/8/2004).

Similarly to Al-Shiab (2006), Katircioglu and Al-khaza'leh (2016) forecasted services sector volatility in Amman Stock Exchange with ARIMA models, using historical indices data accumulated daily over the period (3/1/2010-10/5/2015). They found that the best model for forecasting this stock exchange is ARIMA $(0,0,1)$.

Wahyudi (2017) conducted the prediction of Indonesia stock price using Autoregressive Integrated Moving Average model. He used the daily Indonesia Composite Stock Price Index (CSPI) over the period (04/01/2010 -05/12/2014). He found that ARIMA model has a strong potential for short-term prediction and can compete favorably with the existing techniques for stock price prediction.

Ashik and Kannan (2017) evaluated and predicted the trend of upcoming trading days of the Nifty 50 stock market in India using the Box-Jenkins methodology. They found that the prediction accuracy is more suitable for the Nifty 50 closing stock price. They concluded that the closing stock price of Nifty 50 taken in this study shows a slight decreasing fluctuations trend for upcoming trading days.

Concerning examples of the other fields of forecasting with the Box-Jenkins method, Wagner (2010) forecasted Daily Demand in Cash Supply Chains using a SARIMA model and vector time series model. He found that the seasonal ARIMA model resulted in a higher forecasting accuracy compared to the vector time series model. According to the author, this result confirms the benefit of advanced forecasting techniques for daily forecasts.

Chang et al (2012) predicted the monthly precipitation in Yantai, China, over the period from 1961 to 2011 with seasonal ARIMA model. Their results showed that the model fitted the data well and the stochastic seasonal fluctuation was successfully modeled. Chang et al (2012) concluded that Seasonal ARIMA model is a proper method for modeling and predicting time series of monthly precipitation. 


\section{METHODOLOGIE}

This study adopts the Box Jenkins methodology (Box and Jenkins, 1970). This method consists of the following four steps:

3.1. Model identification: Through this step the degree of $\operatorname{ARIMA}(p, d, q)(P, D, Q)_{S}$ model is determined, where:

$\mathrm{s}$ is the periodicity, $\mathrm{p}$ is the autoregressive (AR) order, $\mathrm{d}$ is the non-seasonal differencing order, $\mathrm{q}$ is the moving average (MA) order, $\mathrm{P}$ is the seasonal AR order, $\mathrm{D}$ is the seasonal differencing and $\mathrm{Q}$ is the seasonal MA order.

Recall that ARIMA (p,d,q) model is an integrated $\operatorname{ARMA}(\mathrm{p}, \mathrm{q})$ including differencing in order to get a stationary time series. The general form of the model is written as follow: (Box et al, 2015)

$$
\varphi(B) x_{t}=\phi(B) \nabla^{d} x_{t}=\theta_{0}+\theta(B) \omega_{t} \text {. }
$$

Where: $\quad \begin{aligned} \theta(B) & =1-\theta_{1} B-\theta_{2} B^{2}-\cdots-\theta_{q} B^{q} . \\ & \varphi(B)=1-\varphi_{1} B-\varphi_{2} B^{2}-\cdots-\varphi_{p} B^{p} .\end{aligned}$

With: $x_{t}$ is the studied time series, $\varphi(B)$ is called the generalized autoregressive operator, $\omega_{t} \sim w n\left(0, \sigma^{2}\right)$ is the Gaussian white noise, $\nabla^{d}$ is the Differencing operator of order d given by $\nabla^{d}=(1-B)^{d}$. B is the backshift operator defined by $B^{k} x_{t}=x_{t-k}, B^{k}$ means backshift $\mathrm{k}$ times.

When $\theta_{0}=0$ the general model can be written as: (Box et al, 2015)

$$
x_{t}=\varphi_{1} x_{t-1}+\ldots+\varphi_{p+d} x_{t-p-d}-\theta_{1} \omega_{t-1}-\ldots-\theta_{q} \omega_{t-q}+\omega_{t}
$$

The multiplicative seasonal autoregressive integrated moving average model, or SARIMA (p, d, q) $(P, D, Q)_{S}$ model is given by: Box et al (2015)

$$
\Phi_{p}\left(B^{S}\right) \phi_{P}(B) \nabla_{S}^{D} \nabla^{d} x_{t}=\Theta_{Q}\left(B^{S}\right) \theta_{q}(B) \omega_{t}
$$

Where:

The seasonal difference component is represented by: $\nabla_{S}^{D}=\left(1-B^{S}\right)^{D}$.

$\Phi_{p}\left(B^{S}\right)$ and $\Theta_{Q}\left(B^{S}\right)$ are polynomials in B represents respectively the seasonal autoregressive and moving average components are given as follow: 


$$
\begin{aligned}
& \Phi\left(B^{S}\right)=1-\Phi_{1} B^{S}-\Phi_{2} B^{2 S}-\ldots-\Phi_{P} B^{P S} . \\
& \Theta\left(B^{S}\right)=1-\Theta_{1} B^{S}-\Theta_{2} B^{2 S}-\ldots-\Theta_{Q} B^{Q S} .
\end{aligned}
$$

\subsubsection{Stationarity:}

The Augmented Dickey-Fuller (ADF) test (Dickey and Fuller, 1979; Said and Dickey, 1984) was employed to determine the order of difference $d$ and to check the stationarity of our time series by testing the presence of unit roots in it.

The objective of this test is to examine the null hypothesis that a unit_root is present in a time series $x_{t}$, which means that $x_{t}$ is not stationary.

The ADF test is performed in the follows form:

$$
\nabla x_{t}=\alpha+\beta t+\gamma x_{t-1}+\delta_{1} \nabla x_{t-1}+\ldots+\delta_{p} \nabla x_{t-p}+\omega_{t}
$$

Where: $\alpha$ is a constant, $\beta$ the coefficient on a time trend and $p$ the lag order of the autoregressive process.

If $x_{t}$ has no trend and no drift then the test can be performed as follows:

$$
\nabla x_{t}=\gamma x_{t-1}+\delta_{1} \nabla x_{t-1}+\ldots+\delta_{p} \nabla x_{t-p}+\omega_{t}
$$

The problem in this test is determining the optimal number of lags $\mathrm{p}$ of the dependent variable. According to Brooks (2008, page 329) the frequency of the data can be used to decide. So, if the data are monthly, we use 12 lags, if the data are quarterly, we use 4 lags, and so on.

The test of HEGY (Hylleberg et al, 1990) can be used to show if there are some seasonal patterns in our time series. The null hypothesis of this test is that a seasonal unit root exists (López-de-Lacalle and Boshnakov, 2019).

\subsubsection{Order selection:}

The ACF and the PACF can be used to determine the orders $\mathrm{p}$ and $\mathrm{q}$ of our model. According to Tsay (2005), by looking at the ACF and PACF plot of a simulated time series. If the ACF cuts off at lag q, this lag is the order of MA. If the PACF cuts off at lag $p$, this lag is the order of AR.

The seasonal MA and AR orders can be determined by showing a significant spike in the seasonal lags of the ACF and PACF functions respectively (Hyndman and Athanasopoulos, 2018).

The Akaike information criteria (AIC) (Akaike, 1974) was used in order to fit the best model and get the appropriate orders $\mathrm{p}, \mathrm{d}, \mathrm{q}$ and $\mathrm{P}, \mathrm{D}, \mathrm{Q}$. The model that gives the lowest AIC value would be selected as the best one (Box et al, 2015). The (AIC) is defined as follows: (Box et al, 2015) 


$$
\mathrm{AIC}=(-2) \log (\text { maximum likelihood })+2 \mathrm{~K} \approx n \log \left(\hat{\sigma}^{2}\right)+2 K
$$

Where:

$\mathrm{K}$ is the number of independently adjusted parameters within the model $\hat{\sigma}^{2}$ is the maximum likelihood estimate of $\sigma^{2}$.

\subsection{Model estimation:}

Maximum likelihood estimation was used to estimate the parameters of the fitted model. The Gaussian Likelihood for a Gaussian ARMA Process with zero mean is given by :( Brockwell and Davis, 2002)

$$
L\left(\phi, \theta, \sigma^{2}\right)=\frac{1}{\sqrt{\left(2 \pi \sigma^{2}\right)^{n}} r_{0} \ldots r_{n-1}} \exp \left\{-\frac{1}{2 \sigma^{2}} \sum_{j=1}^{n} \frac{\left(x_{j}-\hat{x}_{j}\right)^{2}}{r_{j-1}}\right\} .
$$

Where: $\hat{x}_{j}$ and $r_{j}$ are independent of $\sigma^{2}$.

$r_{n}$ is the mean squared error given by $r_{n}=E\left(y_{n+1}-\hat{y}_{n+1}\right)^{2}$, with $y_{t}$ is the transformed process of $x_{t}$ that verify:

$$
\begin{aligned}
& y_{t}=\frac{x_{t}}{\sigma}, \mathrm{t}=1, \ldots, \mathrm{m} . \mathrm{m}=\max (\mathrm{p}, \mathrm{q}), \\
& y_{t}=\frac{\phi(B) x_{t}}{\sigma}, \mathrm{t}>\mathrm{m} .
\end{aligned}
$$

The maximum likelihood estimators $\hat{\phi}, \hat{\theta}$ and $\hat{\sigma}^{2}$ satisfy the following equations (Brockwell and Davis, 2002, p. 160):

$$
\hat{\sigma}^{2}=\frac{S(\hat{\phi}, \hat{\theta})}{n}
$$

Where: $S(\hat{\phi}, \hat{\theta})=\sum_{j=1}^{n} \frac{\left(x_{j}-\hat{x}_{j}\right)^{2}}{r_{j-1}}$.

$\hat{\phi}$ and $\hat{\theta}$ are the values that minimize $\ell(\phi, \theta)=\ln \left(\frac{S(\phi, \theta)}{n}\right)+\frac{\sum_{j=1}^{n} r_{j-1}}{n}$.

For further details see Brockwell and Davis (2002).

\subsection{Model diagnostic:}

The diagnostic checking is necessary to test the adequacy of the selected model. Three diagnostic tests were used in this study: 


\subsubsection{Autocorrelation test:}

We will use the Ljung-Box test to check autocorrelation between residuals. The statistic of this test is given as follow: ( Ljung and Box, 1978)

$$
\tilde{Q}(r)=n(n+2) \sum_{i=1}^{m} \frac{r_{k}^{2}}{(n-k)} .
$$

Where: $\tilde{Q}(r)$ is distributed as $\chi_{m}^{2}$ for a large $\mathrm{n}$,

$n$ is the number of observations and $m$ is the maximum number of lags (the degree of freedom), $\left\{a_{i}\right\}$ is a sequence of independent and identically distributed $N\left(0, \sigma^{2}\right)$ random deviates,

$r_{k}$ is the autocorrelation function (for lag k), given by: $r_{k}=\sum_{i=k+1}^{n} \frac{a_{i} a_{i-k}}{\sum_{i=1}^{n} a_{i}{ }^{2}}$.

The hypotheses of Ljung - Box test are:

$H_{0}: r_{1}=r_{2}=\ldots=r_{n}=0$ (No residuals autocorrelation).

$H_{a}: r_{i} \neq 0$ (Residuals autocorrelation).

The decision rule is to reject $H_{0}$ if $\tilde{Q}(r)>\chi_{m}^{2}$ (Tsay ,2005).

\subsubsection{Heteroskedasticity test:}

The Engle's ARCH test (Engle, 1982) was used to show weather the residuals are heteroskedastic or not. The alternative hypothesis of this Lagrange multiplier (LM) test is that ARCH(p) effects are present in a series of residuals (Drachal, 2017). The procedure of this test consists of the following steps: (Engle, 1982, p.1000)

Running the OLS regression and saving the residuals.

Regressing the squared residuals on a constant and $\mathrm{p}$ lags and test $T R^{2}$ as $\chi_{p}^{2}$.

Where $\mathrm{T}$ is the number of observations and $R^{2}$ is the coefficient of multiple correlations.

\subsubsection{Normality tests:}

Different tests of normality were used in this study such as kolmogorov-Smirnov (Frank and Massey, 1951), Shapiro-Wilk (Shapiro and Wilk, 1965), Anderson-darling (Stephens, 1986), to check the distribution of our time series and residuals. The null hypothesis of these tests is that the sample is normally distributed.

The Q-Q plot and density plot can be used also to check the distribution of time series and residuals. 


\subsection{Forecasting:}

Forecasting is predicting the future values of a time series, based on its available current and past values. According to Box et al (2015) an observation $x_{t+l}$ generated by the ARIMA process can be expressed directly in terms of the difference equation as follow:

$$
x_{t+l}=\varphi_{1} x_{t+l-1}+\ldots+\varphi_{p+d} x_{t+l-p-d}-\theta_{1} \omega_{t+l-1}-\ldots-\theta_{q} \omega_{t+l-q}+\omega_{t+l}
$$

by taking conditional expectations at time $t$ in the previous equation we get the following forecasts from difference equation (Box et al, 2015):

$$
\left[x_{t+l}\right]=\hat{x}_{t}(l)=\varphi_{1}\left[x_{t+l-1}\right]+\ldots+\varphi_{p+d}\left[x_{t+l-p-d}\right]-\theta_{1}\left[\omega_{t+l-1}\right]-\ldots-\theta_{q}\left[\omega_{t+l-q}\right]+\left[\omega_{t+l}\right],
$$

Where: $l$ is the lead time.

$\left[x_{t+l}\right]=E_{t}\left[x_{t+l}\right]=E\left[x_{t+l} / x_{t}, x_{t-1}, \ldots\right]$.

$\left[\omega_{t+l}\right]=E_{t}\left[\omega_{t+l}\right]$

Different measures of forecast accuracy were used to evaluate our forecast are: (Hyndman and Athanasopoulos , 2018)

Mean error: $\mathrm{ME}=$ mean $\left(\mathrm{e}_{t}\right)$.

Where: $e_{t}=x_{t}-\hat{x}_{t}, x_{t}$ is an observed value at time $\mathrm{t}$ and $\hat{x}_{t}$ is the predicted value at the same time $\mathrm{t}$.

Mean absolute error: MAE $=$ mean $\left(\left|\mathrm{e}_{t}\right|\right)$.

Root mean squared error: $\mathrm{RMSE}=\sqrt{\operatorname{mean}\left(\left|\mathrm{e}_{t}^{2}\right|\right)}$.

The mean absolute scaled error (Hyndman and Koehler, 2006): MASE=mean $\left(\left|q_{j}\right|\right)$, where:

$q_{j}=\frac{e_{j}}{\frac{1}{T-m} \sum_{t=2}^{T} x_{t}-x_{t-1}}$ is the scaled error for a non-seasonal time series.

$q_{j}=\frac{e_{j}}{\frac{1}{T-m} \sum_{t=m+1}^{T} x_{t}-x_{t-m}}$ is the scaled error for a seasonal time series.

$\mathrm{m}$ is the seasonal period. 
Note that the Mean absolute percentage error (MAPE) can't be used in this case study because our data contains zero values.

\section{DATA AND EMPIRICAL RESULTS}

\subsection{Exploratory data analysis:}

The empirical analysis in this study was conducted using R software version 3.5.3.

The data were collected from the official website of Algiers Stock Exchange. Due to a lot of missing values of daily closing prices for the ASE index (DZAIRINDEX), monthly observations were used by taking the closing price values of the ASE index on each month-end. The period of study was from Jun 2010 to July 2019. Returns $\left(r_{t}\right)$ were calculated similarly to Chou (1988) but by taking monthly observations as in Emenike (2010) where:

$$
r_{t}=\log \left(P_{t} / P_{t-1}\right)
$$

$P_{t}$ and $P_{t-1}$ represent the closing price of the ASE index for the current month and the previous respectively.

The time series plot of the monthly DZAIRINDEX returns $\left(r_{t}\right)$ is shown in Figure 1. We can see from the plot that our time series has no trend and no drift. We deduce also easily from the Q-Q plot (Figure 2 ) and the density plot (Figure 3 ) that $r_{t}$ time series is not normally distributed.

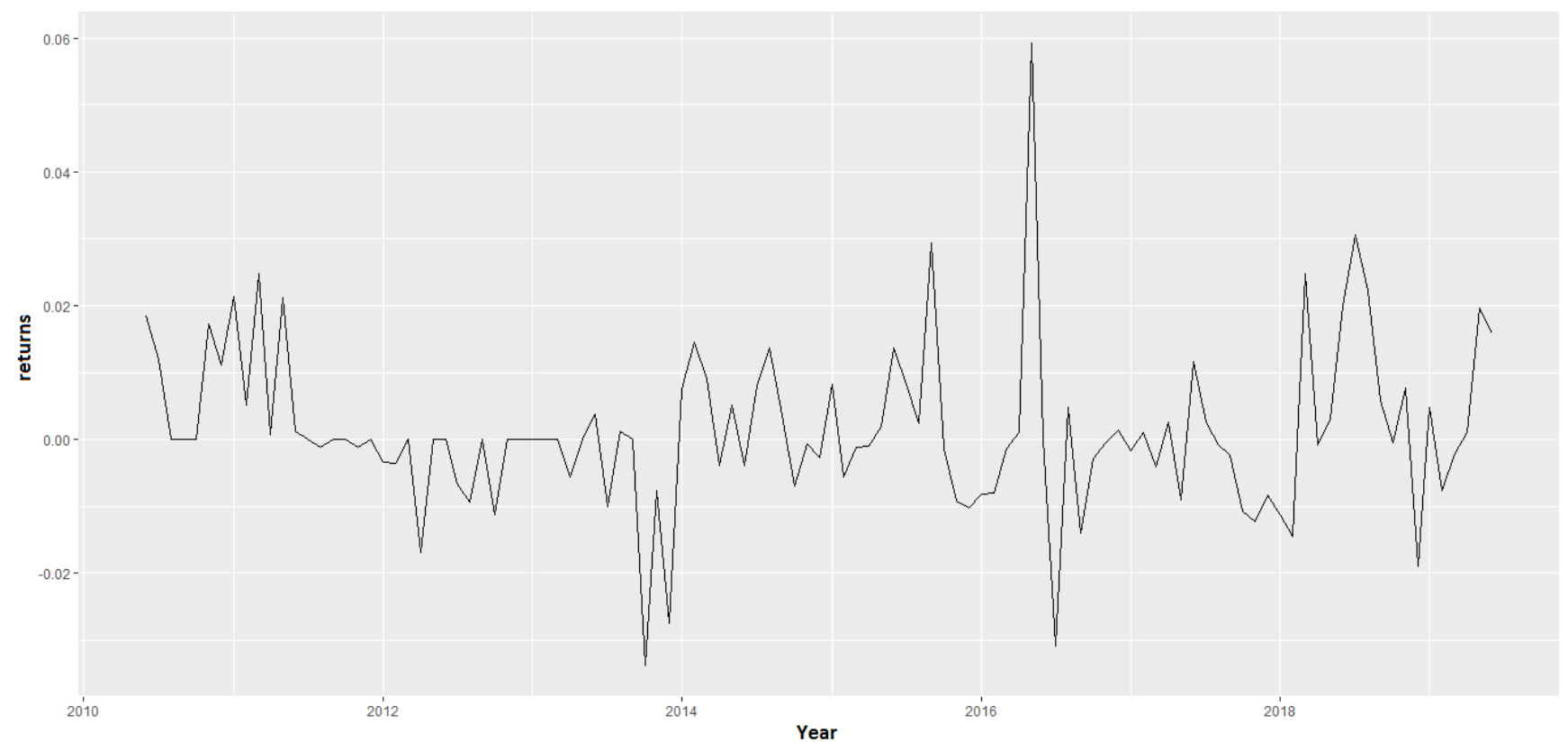

Figure 1-Time series plot of the monthly DZAIRINDEX returns 


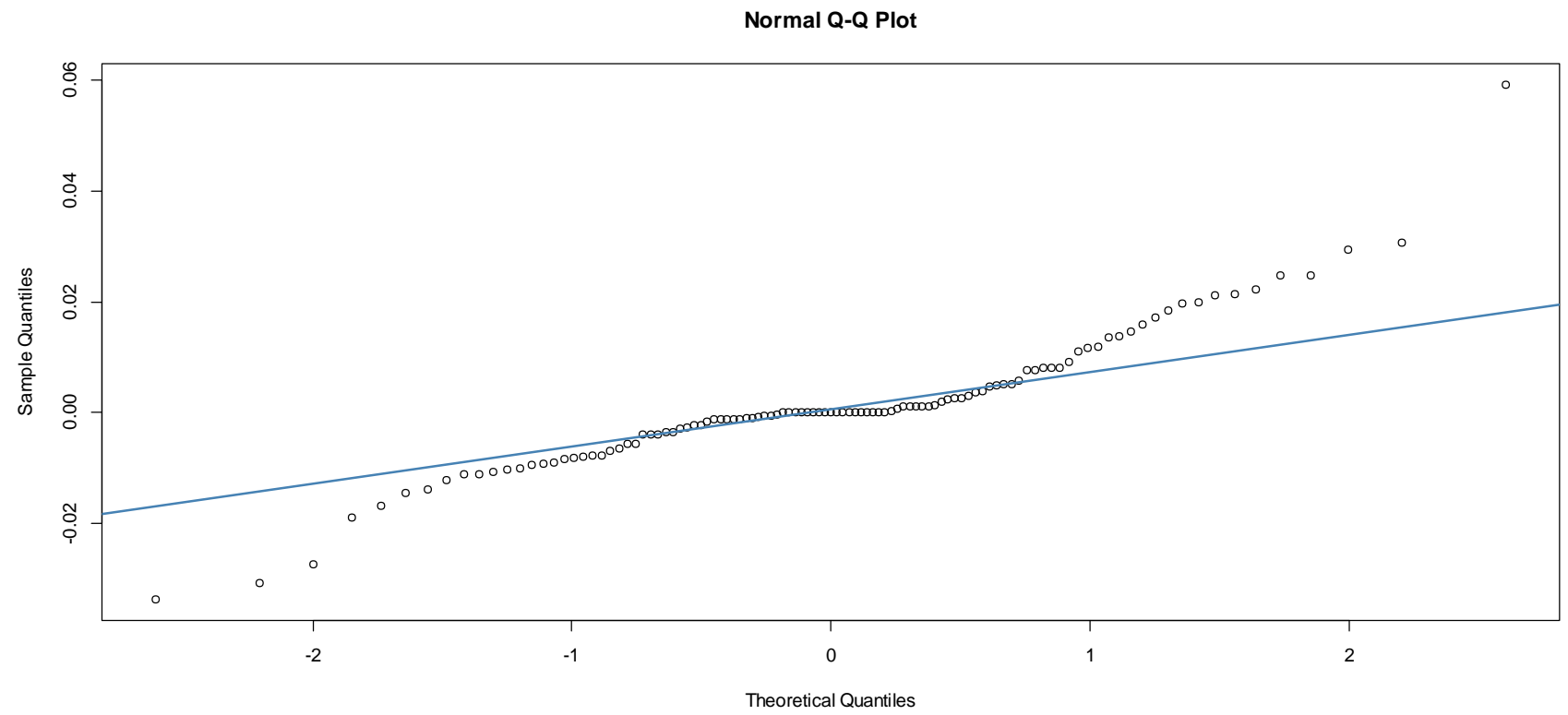

Figure 2- Q-Q Plot of the monthly DZAIRINDEX returns time series

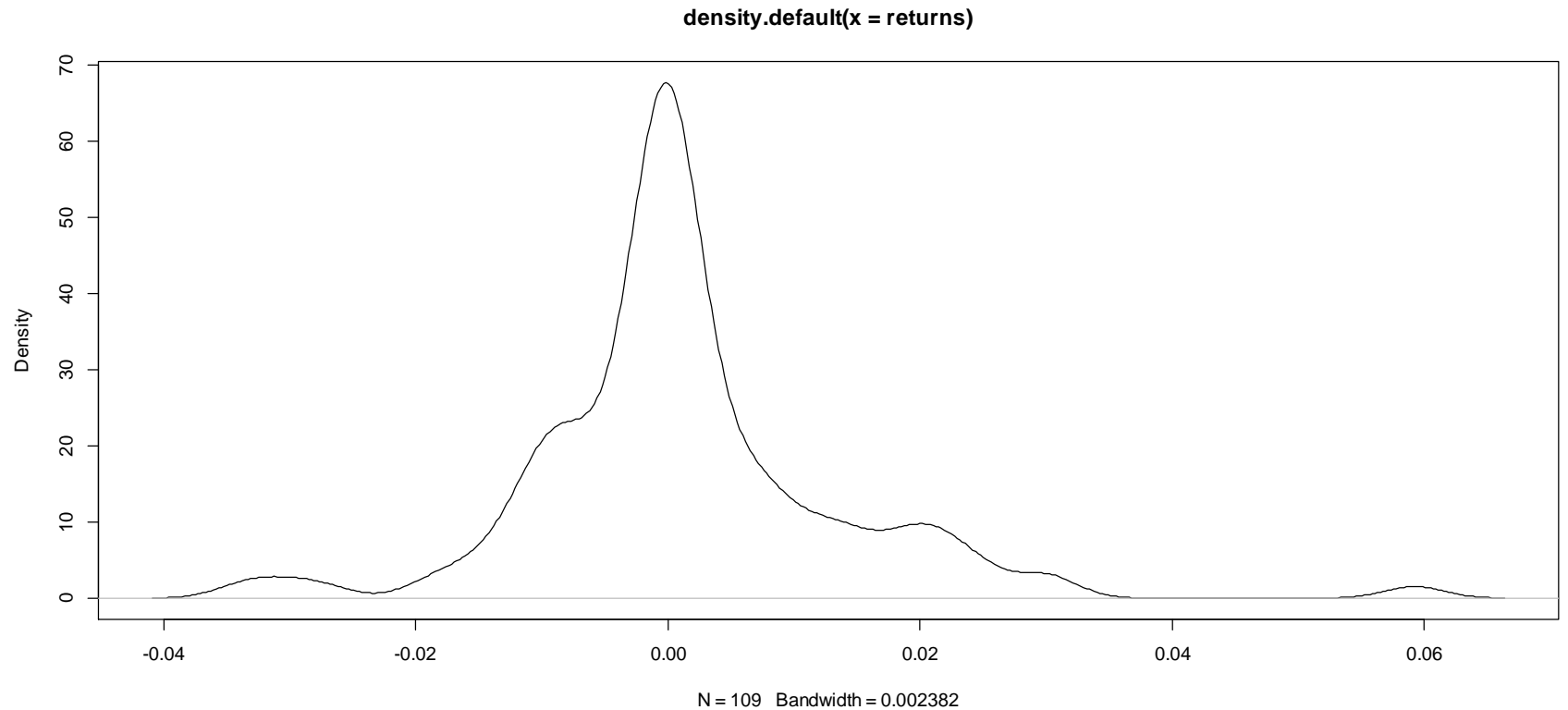

Figure 3-Density plot of DZAIRINDEX monthly returns time series

Table1below shows a summary statistics of $r_{t}$ time series

\begin{tabular}{|l|ccccccccccc|}
\hline & $\mathrm{n}$ & Mean & $\mathrm{Sd}$ & Median & Trimmed & Mad & Min & Max & Range & Skew & kurtosis \\
\hline returns & 109 & 0 & 0.01 & 0 & 0 & 0.01 & -0.03 & 0.06 & 0.09 & 0.89 & 4.18 \\
\hline
\end{tabular}

Table 1- Summary statistics of the monthly DZAIRINDEX returns 
The HEGY test (Table 2) shows that $r_{t}$ time series has some seasonal patterns, where all the p-values of this test statistics are not significant at 0.05 level.

\begin{tabular}{|lll|}
\hline \multicolumn{3}{|c|}{ HEGY test for unit roots } \\
\hline Data: & $r_{t}$ \\
\hline & Statistic & p-value \\
\hline t_1 & -1.9654 & 0.2302 \\
\hline t_2 & -1.0452 & 0.192 \\
\hline F_3:4 & 1.2583 & 0.2411 \\
\hline
\end{tabular}

Table 2- HEGY test

Before start applying the Box-Jenkins procedure, outliers were replaced using linear interpolation, then returns time series was seasonally adjusted by removing the seasonal component using STL decomposition (Hyndman and Athanasopoulos , 2018). See also Hyndman and Khandakar (2008) and Hyndman et al (2019). Figure 4 shows the STL decomposition for the monthly DZAIRINDEX returns time series.

These two tasks transform $r_{t}$ into normally distributed time series, which is important in ARIMA model estimation and order selection. The result of Kolmogrove -Smirnov test in Table 3 shows that the monthly DZAIRINDEX returns can be assumed normally distributed after replacing outliers and seasonality adjustment. The assumption of normality is essential to get efficient and consistent maximum likelihood estimation. Note that in this case study we can't use the Box-Cox transformation (Box and Cox, 1964) because our data contains zero values.

Figure 5 shows the plot of monthly returns time series $r_{t}$ before and after replacing outliers and seasonality adjustment. In the next of this study, the seasonally adjusted $r_{t}$ time series with replaced outliers is noted by $y_{t}$.

\begin{tabular}{|lcc|}
\hline Test & Statistic & p-value \\
\hline Kolmogorov-Smirnov & 0.0753 & 0.5663 \\
\hline & & \\
\hline
\end{tabular}

Table 3- Kolmogorov-Smirnov test of normality for $y_{t}$ time series 


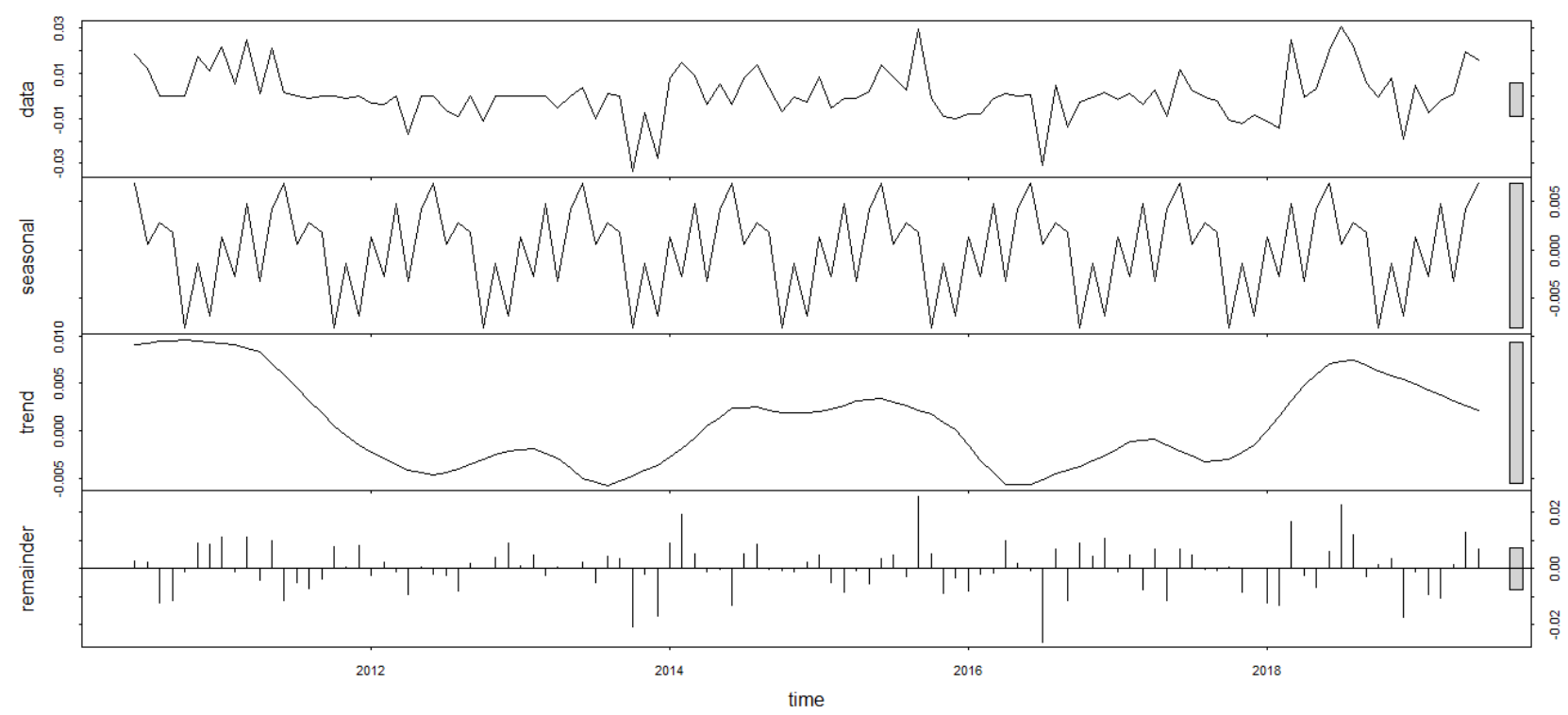

Figure 4- STL decomposition of the monthly DZAIRINDEX returns.

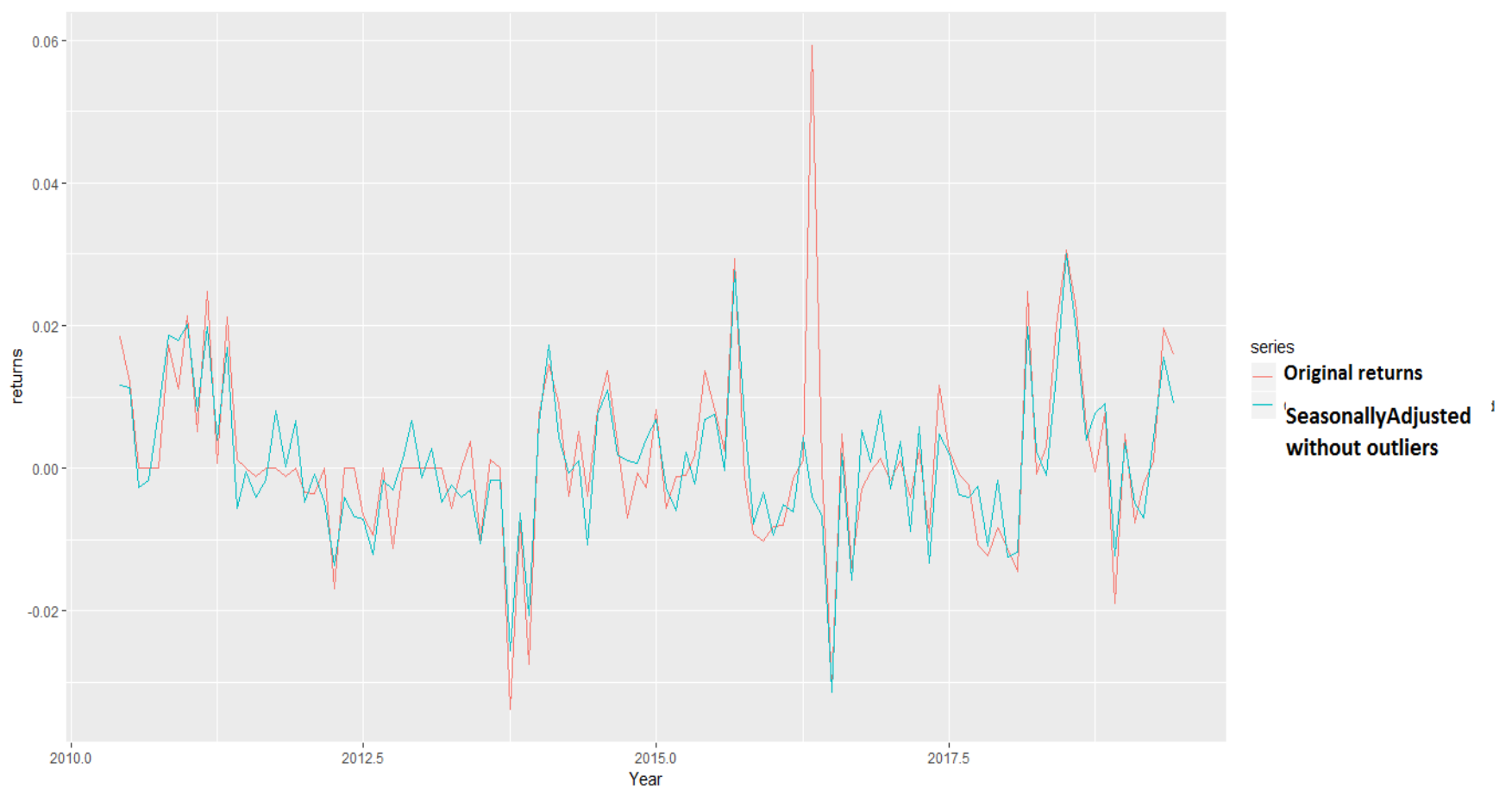

Figure 5- The monthly DZAIRINDEX returns after outliers replacing and seasonality adjustment 
The Mann-Kendall test (McLeod, 2015) can be used to check if the time series $y_{t}$ has a trend. The results of this test are given in Table 4 . At 0.05 level of significance, the p-value of this test statistic is not significant. This leads us to accept the null hypothesis that $y_{t}$ hasn't a trend.

\begin{tabular}{|c|c|c|}
\hline \multicolumn{3}{|c|}{ Mann-Kendall trend test } \\
\hline \multicolumn{3}{|c|}{ data: $y_{t}$ time series } \\
\hline $\mathrm{n}=109$ & $z=-0.47136$ & $\mathrm{p}$-value $=0.6374$ \\
\hline
\end{tabular}

Table 4. Mann- Kendall trend test

We can also confirm that $y_{t}$ hasn't a drift by running an autoregressive model with drift then we check the significance of the intercept, as it is shown in Table 5. The result of this procedure shows that the intercept is not significant at the 0.05 level. This means that the time series $y_{t}$ hasn't a drift.

\begin{tabular}{|lllll|}
\hline \multicolumn{7}{|c|}{ Test regression drift } \\
\hline \multicolumn{5}{|c|}{ Coefficients: } \\
\hline & Estimate & Std. Error & t value & $\operatorname{Pr}(>|\mathrm{t}|)$ \\
\hline (Intercept) & -0.0002396 & 0.0009827 & -0.244 & 0.80796 \\
\hline z.lag.1 & -0.7335279 & 0.2617452 & -2.802 & 0.00633 \\
\hline z.diff.lag1 & -0.0300567 & 0.2456352 & -0.122 & 0.90291 \\
\hline z.diff.lag2 & 0.1276535 & 0.2329661 & 0.548 & 0.58522 \\
\hline z.diff.lag3 & 0.1212361 & 0.2151391 & 0.564 & 0.57462 \\
\hline
\end{tabular}

Source: Output of R software

Table 5- Test regression drift

\subsection{Model identification:}

Since $y_{t}$ is a monthly time series with no drift and no trend we have chosen the ADF test with 12 lags and without a trend and a drift. The result of this test is given in Table 6. From this table, we see that all the p-values of ADF test statistics are significant at 0.05 level. This means a rejection of the null hypothesis that $y_{t}$ is not stationary. Hence $y_{t}$ is stationary. 


\begin{tabular}{|c|c|c|}
\hline \multicolumn{3}{|c|}{ Augmented Dickey-Fuller Test } \\
\hline \multicolumn{3}{|c|}{ Alternative hypothesis: Stationary } \\
\hline \multicolumn{3}{|c|}{ Type: No drift, no trend } \\
\hline Lag & ADF & $\mathrm{p}$-value \\
\hline 0 & -7.52 & 0,01 \\
\hline 1 & -4.84 & 0,01 \\
\hline 2 & -4.28 & 0,01 \\
\hline 3 & -3.88 & 0,01 \\
\hline 4 & -3.81 & 0,01 \\
\hline 5 & -3.47 & 0,01 \\
\hline 6 & -3.64 & 0,01 \\
\hline 7 & -3.40 & 0,01 \\
\hline 8 & -3.28 & 0,01 \\
\hline 9 & -3.47 & 0,01 \\
\hline 10 & -2.90 & 0,01 \\
\hline 11 & -3.42 & 0,01 \\
\hline
\end{tabular}

Table 6- The augmented Dickey Fuller test of stationarity

Figure 6 and Figure 7 show the correlograms of the autocorrelation function (ACF) and the partial autocorrelation function (PACF) respectively. The summary of the candidate ARIMA models according to the AIC estimator is given in Table 7. Based on the results of this estimation, $\operatorname{SARIMA}(2,0,0)(0,0,1)_{12}$ model with zero mean is selected as the best model because it shows the lowest AIC value. This means that the time series $y_{t}$ still has some seasonal patterns.

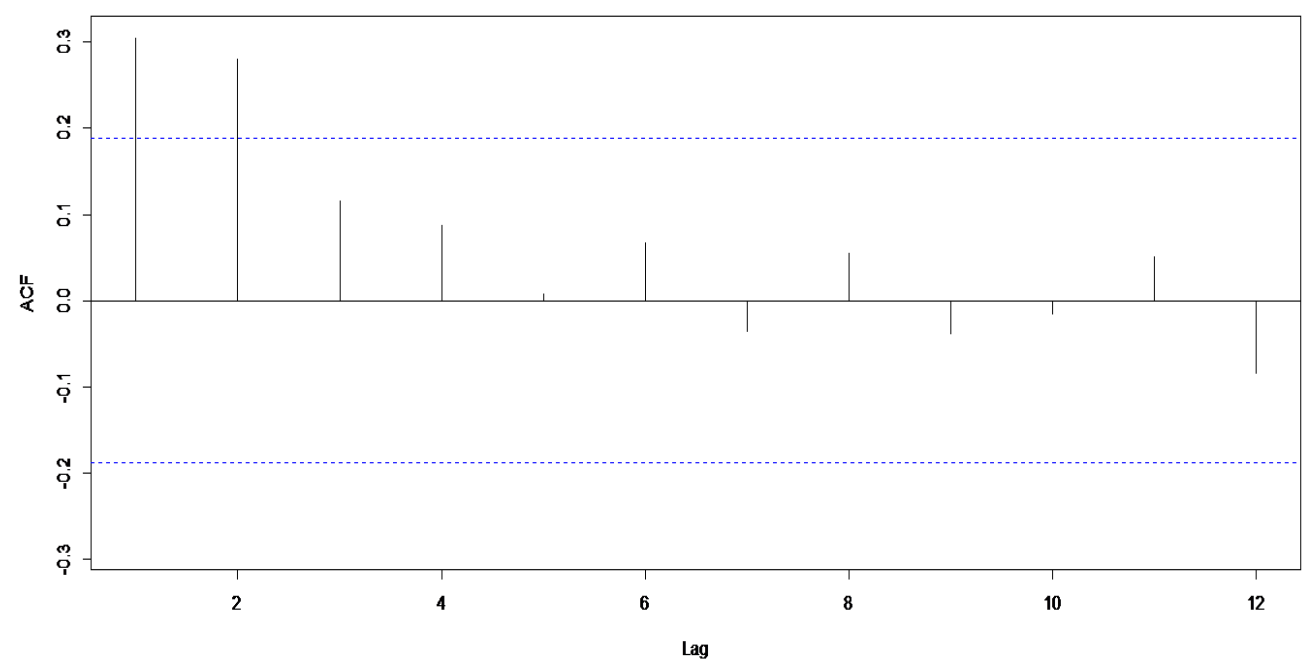

Figure 6- The autocorrelation function of $y_{t}$ time series 


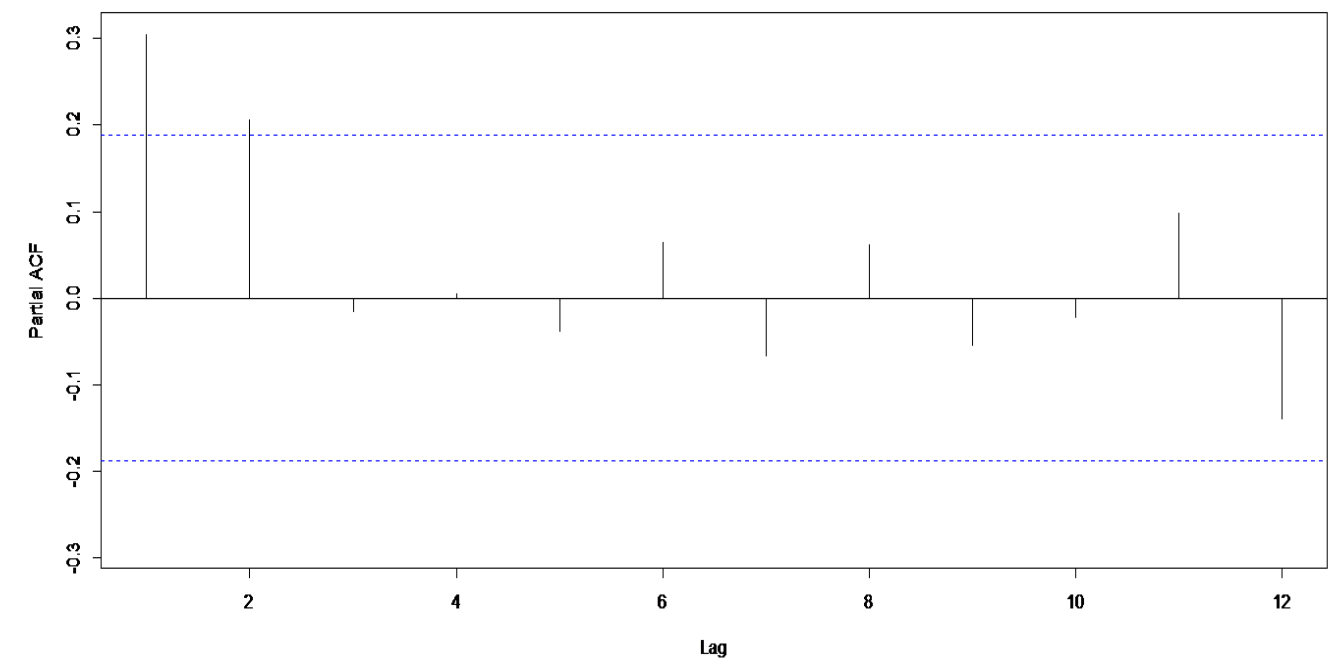

Figure 7- The partial autocorrelation function of $y_{t}$ time series

\begin{tabular}{|c|c|}
\hline Models & AIC \\
\hline $\operatorname{ARIMA}(2,0,2)(1,0,1)[12]$ with non-zero mean & Inf \\
\hline $\operatorname{ARIMA}(0,0,0) \quad$ with non-zero mean & -691.2342 \\
\hline $\operatorname{ARIMA}(1,0,0)(1,0,0)[12]$ with non-zero mean & -699.5073 \\
\hline $\operatorname{ARIMA}(0,0,1)(0,0,1)[12]$ with non-zero mean & -697.1523 \\
\hline $\operatorname{ARIMA}(0,0,0) \quad$ with zero mean & -692.5961 \\
\hline with non-zero mean & -700.0314 \\
\hline $\operatorname{ARIMA}(1,0,0)(0,0,1)[12]$ with non-zero mean & -700.7933 \\
\hline $\operatorname{ARIMA}(1,0,0)(1,0,1)[12]$ with non-zero mean & Inf \\
\hline $\operatorname{ARIMA}(1,0,0)(0,0,2)[12]$ with non-zero mean & Inf \\
\hline $\operatorname{ARIMA}(1,0,0)(1,0,2)[12]$ with non-zero mean & Inf \\
\hline $\operatorname{ARIMA}(0,0,0)(0,0,1)[12]$ with non-zero mean & -692.0527 \\
\hline $\operatorname{ARIMA}(2,0,0)(0,0,1)[12]$ with non-zero mean & -703.8522 \\
\hline $\operatorname{ARIMA}(2,0,0) \quad$ with non-zero mean & -703.233 \\
\hline $\operatorname{ARIMA}(3,0,0)(0,0,1)[12]$ with non-zero mean & -702.2476 \\
\hline $\operatorname{ARIMA}(2,0,1)(0,0,1)[12]$ with non-zero mean & -702.8139 \\
\hline $\operatorname{ARIMA}(1,0,1)(0,0,1)[12]$ with non-zero mean & -702.0572 \\
\hline $\operatorname{ARIMA}(3,0,1)(0,0,1)[12]$ with non-zero mean & -701.4519 \\
\hline $\operatorname{ARIMA}(2,0,0)(0,0,1)[12]$ with zero mean & -705.6575 \\
\hline $\operatorname{ARIMA}(2,0,0) \quad$ with zero mean & -704.8566 \\
\hline $\operatorname{ARIMA}(2,0,1)(0,0,1)[12]$ with zero mean & -704.6898 \\
\hline
\end{tabular}

Table 7- Summary of the fitted ARIMA models based on AIC estimation. 


\subsection{Model estimation:}

The Maximum likelihood was used to estimate the parameters of our model SARIMA $(2,0,0)(0,0,1)_{12}$. The estimates of the parameters are presented in Table 8 below. We see that all the coefficients are significant at different levels. This implies the appropriateness of this model.

\begin{tabular}{|c|c|c|c|c|}
\hline \multicolumn{5}{|c|}{$z$ test of coefficients } \\
\hline & Estimate & Std. Error & $\mathrm{z}$ value & $\operatorname{Pr}(>|z|)$ \\
\hline ar1 & 0.248510 & 0.093472 & 2.6587 & $0.007845 * *$ \\
\hline $\operatorname{ar} 2$ & 0.215048 & 0.094735 & 2.2700 & $0.023208 *$ \\
\hline sma & -0.244925 & 0.150485 & -1.6276 & 0.103616 \\
\hline
\end{tabular}

Table 8- Estimation of model parameters

\subsection{Model diagnostic:}

Box-Ljung and Engle'LM tests were used to check respectively the autocorrelation and the Heteroskedasticity in residuals of the fitted model. The results of these two tests are respectively represented in Tables 9 and 10. We show that both p-values of these two tests statistics are not significant at 0.05 level. This implies an acceptance of the null hypotheses that residuals have no autocorrelation and no Heteroskedasticity respectively.

\begin{tabular}{|l|l|l|}
\hline \multicolumn{3}{|c|}{ Box-Ljung test } \\
\hline Data: & Residuals of SARIMA $(2,0,0)(0,0,1)_{12}$ \\
\hline $\mathrm{df}=12$ & $\chi$-squared $=4.4512$ & $\mathrm{p}$-value $=0.9739$ \\
\hline
\end{tabular}

Source: Output of R software

Table 9- Box-Ljung test of autocorrelation.

\begin{tabular}{|c|c|c|}
\hline \multicolumn{3}{|c|}{ Engle's LM ARCH Test } \\
\hline \multicolumn{3}{|c|}{ Data: Residuals of SARIMA $(2,0,0)(0,0,1)_{12}$} \\
\hline \multicolumn{3}{|c|}{ Alternative hypothesis: ARCH effects of order 12 are present } \\
\hline $\operatorname{Lag}=12$ & Statistic $=15.614$ & $p$-value $=0.2096$ \\
\hline
\end{tabular}

Table 10- Engle's LM Test of heteroskedasticity. 
Different tests of normality show also that the residuals of $\operatorname{SARIMA}(2,0,0)(0,0,1)_{12}$ are normally distributed. See Table 11 below.

\begin{tabular}{|lcc|}
\hline \multicolumn{1}{|c|}{ Test } & Statistic & pvalue \\
\hline Shapiro-Wilk & 0.9804 & 0.1097 \\
Kolmogorov-Smirnov & 0.0801 & 0.4865 \\
Anderson-Darling & 0.6685 & 0.0788 \\
\hline
\end{tabular}

Source: Output of R software

Table 11- Normality tests of residuals

All these diagnostic tests confirm the adequacy of our fitted model for forecasting the time series $y_{t}$.

\subsection{Forecasting:}

After adding back the seasonal component and the outliers, the forecast of the original monthly returns $r_{t}$ time series shows a decreasing fluctuations trend in the upcoming months. See Figure 8.

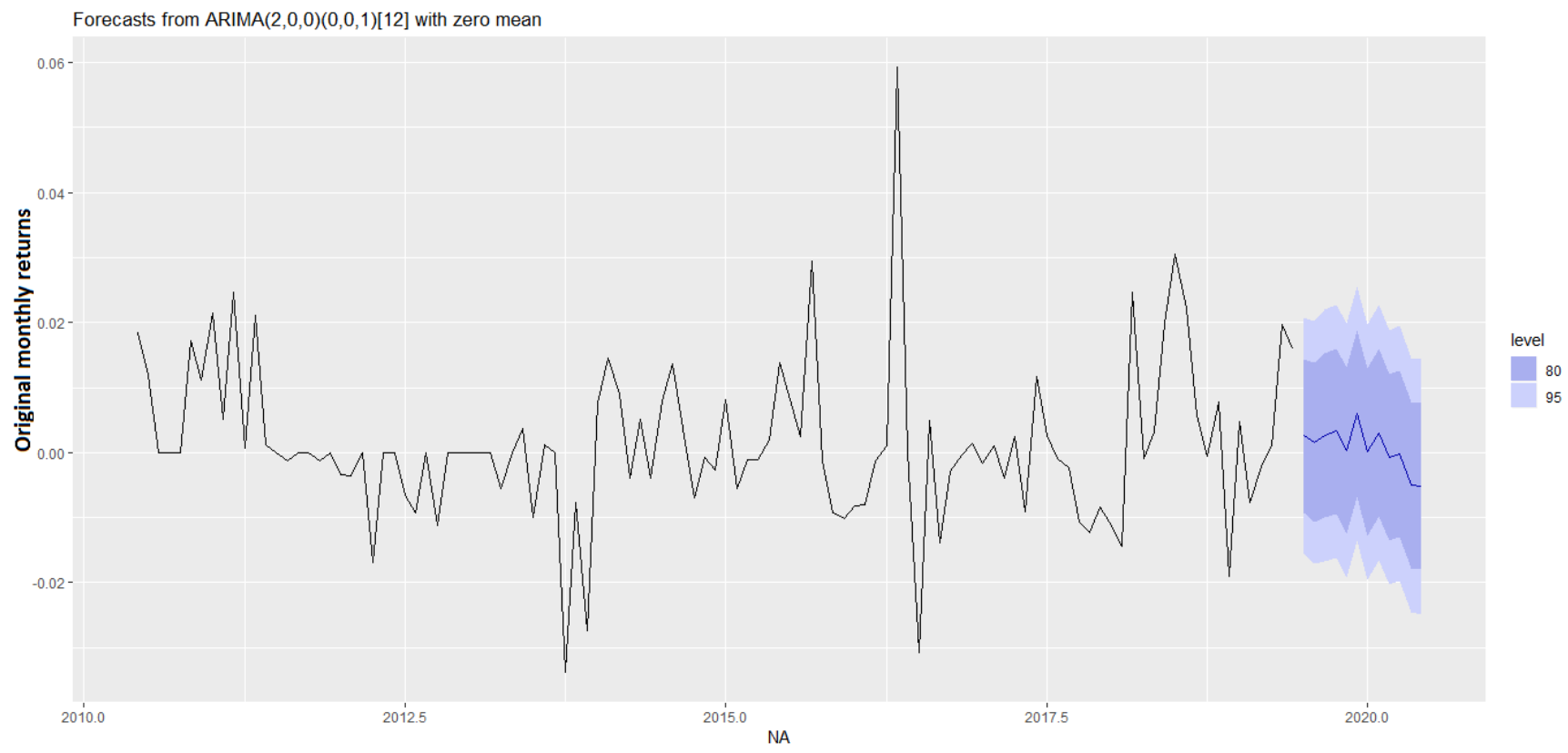

Figure 8- The monthly DZAIRINDEX returns forecast. 
The forecast accuracy for the original monthly returns time series using $\operatorname{SARIMA}(2,0,0)(0,0,1)_{12}$ is represented in Table 12. Different error measurements show that the forecast accuracy of our model is acceptable. The MASE value is less than 1, this implies that $\operatorname{SARIMA}(2,0,0)(0,0,1)_{12}$ performs much better than a naïve model in this case study (Hyndman and Athanasopoulos, 2018 ).

\begin{tabular}{|l|lllr|}
\hline Model & ME & RMSE & MAE & MASE \\
\hline SARIMA $(2,0,0)(0,0,1)_{12}$ & 0.00096 & 0.01248 & 0.00833 & 0.69727 \\
\hline
\end{tabular}

Table 12- Accuracy of forecasting the monthly DZAIRINDEX returns with $\operatorname{SARIMA}(2,0,0)(0,0,1)_{12}$

\section{CONCLUSION}

This study used the Box-Jenkins methodology for forecasting the monthly DZAIRINDEX returns time series. Based on this approach, the seasonal $\operatorname{ARIMA}(2,0,0)(0,0,1)_{12}$ was found as the best model to forecast the studied time series. The forecasts of monthly returns for one year ahead shows a decreasing fluctuations trend. Different measures of forecast accuracy confirm that the forecast performance of our model is acceptable and it is better than a naïve model. We conclude from the results of this study that the seasonal ARIMA $(2,0,0)(0,0,1)_{12}$ model could be used by policymakers and investors in Algeria for forecasting the Algiers Stock Exchange, in order to get better investment decisions and returns.

The main limitation of the ARIMA model is the pre-assumed linear form of the model (Kumar and Thenmozhi , 2012). Most stock market time series are basically non-linear. So, the use of nonlinear models for forecasting the Algiers Stock Exchange may give a better forecast accuracy from the ARIMA model. 


\section{REFERENCES}

[1] Akaike, H. (1974). A new look at the statistical model identification, IEEE Transactions on Automatic Control, AC-19, 716--723.

[2] Al-Shiab, M. (2006). The Predictability of the Amman Stock Exchange using the Univariate Autoregressive Integrated Moving Average (ARIMA) Model, Journal of Economic and Administrative Sciences, Vol. 22 Iss 2 pp. 17 - 35

[3] Ashik, M. A and Kannan, S. K. (2017). Forecasting national stock price using ARIMA model. Glob Stoch Anal 4(1): 77-81.

[4] Box, G. E. P. and Cox, D. R. (1964). An analysis of transformations, Journal of the Royal Statistical Society, Series B, 26, 211-252.

[5] Box, G. E. P and Jenkins, G. M. (1970). Time series analysis: Forecasting and control. San Francisco: Holden-Day.

[6] Box, G. E. P and Jenkins, G.M. (1976). Time Series Analysis: Forecasting and Control. San Fransisco: Holden Day.

[7] Box, G. E. P., Jenkins, G. M., Reinsel, G. C., and Ljung, G. M. (2015). Time series analysis: Forecasting and control (5th ed). Hoboken, New Jersey: John Wiley \& Sons.

[8] Brockwell, P.J and Davis, A.R. (2002). An Introduction to Time Series and Forecasting. 10.1007/978-1-4757-2526-1.

[9] Chang, X., Gao, M., Wang, Y., and Hou, X. (2012). Seasonal autoregressive integrated moving average model for precipitation time series. Journal of Mathematics and Statistics. 8. 500-505. 10.3844/jmssp.2012.500.505.

[10] Chou, R.Y. (1988). Volatility Persistence and Stock Valuations-Some Empirical Evidence Using GARCH. Journal of Applied Econometrics, 3, pp. 279-294.

[11] Brooks, C. (2002). Introductory econometrics for finance, first edition, Cambridge University press, Cambridge.

[12]Dickey, D. A. and Fuller, W. A. (1979). Distribution of the estimates for autoregressive time series with a unit root, J. Am. Stat. Assoc., 74, 427--431. 
[13]Drachal, K.( 2017). fDMA: Dynamic Model Averaging and Dynamic Model Selection for continuous outcomes. https://CRAN.R-project.org/package=fDMA

[14] Engle, R. F. (1982). Autoregressive Conditional Heteroskedasticity with Estimates of the Variance of UK Inflation. Econometrica 50, PP. 987-1008.

[15] Emenike, K. (2010). Modelling Stock Returns Volatility In Nigeria Using GARCH Models. University Library of Munich, Germany, MPRA Paper.

[16] Frank, J and Massey, Jr. (1951) The Kolmogorov-Smirnov Test for Goodness of Fit, Journal of the American Statistical Association, 46:253, 68-78.

[17] Gujarati, D.N. (2004). Basic Econometrics. 4th Edition, McGraw-Hill Companies. New York.

[18] Hylleberg, S., Engle, R., Granger, C. and Yoo, B. (1990). Seasonal integration and cointegration. Journal of Econometrics 44(1), pp. 215-238.

[19] Hyndman, R.J and Athanasopoulos, G. (2018). Forecasting: principles and practice, $2^{\text {nd }}$ edition, OTexts: Melbourne, Australia. OTexts.com/fpp2. Accessed on August 2019.

[20] Hyndman, R. J and Khandakar, Y. (2008). Automatic time series forecasting: The forecast package for R. Journal of Statistical Software, 27(1), 1-22.

[21] Hyndman R, Athanasopoulos G, Bergmeir C, Caceres G, Chhay L, O'Hara-Wild M, Petropoulos F, Razbash S, Wang E, Yasmeen F (2019). forecast: Forecasting functions for time series and linear models. R package version 8.9, http://pkg.robjhyndman.com/forecast.

[22] Hyndman, R. J and Koehler, A. B. (2006). Another look at measures of forecast accuracy. International Journal of Forecasting, 22, 679-688.

[23] Katircioglu, S.T and Al-khaza'leh, M.M. (2016). Modeling daily Amman Stock Exchange volatility for services sector, Journal of Business, Economics and Finance (JBEF), ISSN: 2146 7943

[24] Kumar, M and Thenmozhi, M. (2012). A Comparison of Different Hybrid ARIMA - Neural Network Models for Stock Index Return Forecasting and Trading Strategy. International Journal of Financial Management, 1(1).

[25] Lin, T-W and Yu, C-C. (2009). Forecasting Stock Market with Neural Networks. Available at SSRN: https://ssrn.com/abstract=1327544 
[26] Ljung, G. M, Box, G.E.P. (1978). On a measure of lack of fit in time series models. Biometrika 65:297-303.

[27] López-de-Lacalle, J and Boshnakov, G. N. (2019). Package "uroot”. Available at: https://cran.rproject.org/web/packages/uroot/uroot.pdf

[28] McLeod, A.I. (2015). Package “Kendall”. Available at: https://cran.r- project.org /web/ packages/ Kendall/Kendall.pdf (accessed on 15 May 2019).

[29] Stephens, M.A. (1986). Tests based on EDF statistics. In: D'Agostino, R.B. and Stephens, M.A., eds.: Goodness-of-Fit Techniques. Marcel Dekker, New York.

[30] Said, S. E. and Dickey, D. A. (1984). Testing for unit roots in autoregressive-moving average models of unknown order, Biometrika, 71, 599--607.

[31] Tsay, R. S. (2005). Analysis of financial time series. Hoboken, NJ: Wiley-Interscience. ISBN: 978-0-471-69074-0.

[32] Wahyudi, S. T. (2017). The ARIMA model for the Indonesia stock price. International Journal of Economics and Management. 11. 223-236.

[33] Wagner, M. (2010). Forecasting Daily Demand in Cash Supply Chains. American Journal of Economics and Business Administration. 2. 10.3844/ajebasp.2010.377.383. 